\title{
DIGITAL CARBON MONOXIDE DETECTOR /11/
}

\author{
J.P. DAUCHOT, A. HECQ and M.T. GROGNIA \\ Service de Chimie Inorganique Université de l'Etat à Mons, B-7000 Mons, Belgium
}

(Received October 3 1981; in final form November 2 1981)

The switch off concentration phenomena in carbon monoxide oxidation on platinum and the parallel steep variation of resistance or surface potential of thin platinum films are used to develop a carbon detector. Coating the platinum film with an increasing thickness of polytetrafluorethylene (PTFE) makes this switch off point move to increasing $\mathrm{CO}$ concentrations. Therefore, a series of electrical elements, platinum thin film resistances, platinum M.O.S. diodes or platinum gate M.O.S. transistors covered by calibrated thicknesses of PTFE will switch off at well determined CO concentrations and can continue the basis of a digital detector.

\section{INTRODUCTION}

It was shown earlier that carbon monoxide oxidation on platinum has a typical kinetic behaviour. ${ }^{1,2}$ The reaction rate rises linearly with the ratio $\mathrm{CO} / \mathrm{O}_{2}$ in the gas phase and stops abruptly for a critical ratio at a given temperature (Figure 1). An interpretation of this behaviour was given by Dagonnier and al. ${ }^{3}$ Due to the Langmuir-Hinshelwood mechanism, mixed adsorbates cannot exist beyond a critical $\mathrm{CO}$ concentration at constant temperature or under a critical temperature at constant $\mathrm{CO}$ concentration. On the other hand, at constant temperature, under the critical $\mathrm{CO}$ concentration, the oxygen coverage variation is low. Therefore any property such as electrical resistivity (for thin films), or surface potential depending on the oxygen coverage, will only vary significantly and abruptly at the inhibition point.

Provided that care is taken to reproduce exactly the method of preparing the samples, good reproducibility of this critical point is obtained. After calibration, it can be a measure of the $\mathrm{CO}$ concentration.

By placing on the surface a membrane permeable to the gases (PTFE) this forms a mass transfer resistance for both $\mathrm{CO}$ and $\mathrm{O}_{2}$, so that it is possible to determine the value of the $\mathrm{CO}$ concentration that can be detected.

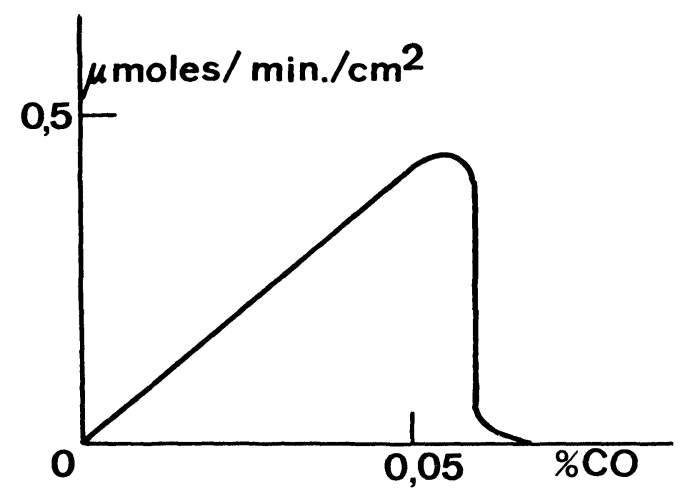

FIGURE 1 Reaction rate as a function of $[\mathrm{CO}] /\left[\mathrm{O}_{2}\right]$ ratio at $135 \mathrm{C}^{\circ}$. 


\section{SAMPLES PREPARATION}

2.1 Circuits. In order to simplify the preparation, the samples used here are thin film resistances of platinum (thickness $\simeq 100 \AA$ ). A variation of electrical resistance of 5 to $10 \%$ is observed when the surface of the film is passed from $\mathrm{CO}$ to $\mathrm{O}_{2}$ coverage. Any other element sensitivitive to adsorbate composition such as MOS tunnel diode ${ }^{4}$ or platinum gated MOS transistor ${ }^{5}$ can be employed to five larger signals but they are less easy to prepare.

The circuits utilized in Figure 2 are obtained by classical photolithography with lift off technique for resistances sizing. The smallness of the resistances in comparison with the substrate avoids excessive heating of the catalyst surface by the reaction itself. The sample to be tested is pasted with silver lacquer on a thermostabilized gold plated copper block in an infrared absorption cell.

2.2 Films. The films are obtained as $\mathrm{PtO}_{2}$ by $\mathrm{DC}$ reactive sputtering of platinum in an Argon-Oxygen mixture ${ }^{6}$ and stocked in this form. On this $\mathrm{PtO}_{2}$ the wanted thickness of PTFE is deposited by R.F. sputtering of a cooled massive PTFE cathode in an argon-CF 4 mixture. ${ }^{7}$ The thickness of the membrane is measured after deposition by the Tolansky method. ${ }^{8}$

2.3 Measurement system. The electrical resistance of each sample is followed as a function of the $\mathrm{CO}$ concentration measured by Infrared absorption. The sample is put in the cell and the CO concentration is slowly increased (quasistatic system) by a needle valve progressively opened until the inhibition point is obtained (Figure 3).

\section{MODEL AND MEASUREMENTS}

The system Gas/PTFE/Platinum as pictured in Figures 4.1 and 2 has two interfaces:

1 is the interface Pt/PTFE and 2 the interface PTFE/gas. The two reacting gases will dissolve in the PTFE at the interface 2, diffuse to the interface 1, be adsorbed on the Pt and react on the $\mathrm{Pt}$ surface. The $\mathrm{CO}_{2}$ formed during the reaction could be retained near the surface because of the membrane but its adsorption energy is so small that it does not influence the reaction rate.

It can be assumed the gas flow is large enough so that no gradient exists in the gas phase. Therefore the oxygen and carbon monoxide gradient are only in the PTFE. On the other hand, in the region where the reaction occurs the $\mathrm{CO}$ partial pressure is low compared to oxygen. Thus small oxygen partial pressure variations in the gas phase will have a negligible effect at the interface 1 and we need only take account of CO dissolu-

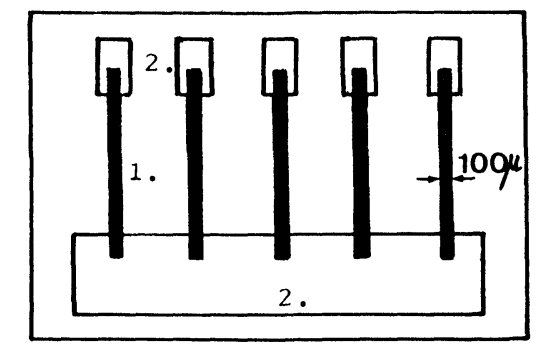

FIGURE 2 Thin film resistances. 1. Platinum. 2. Gold contacts. 


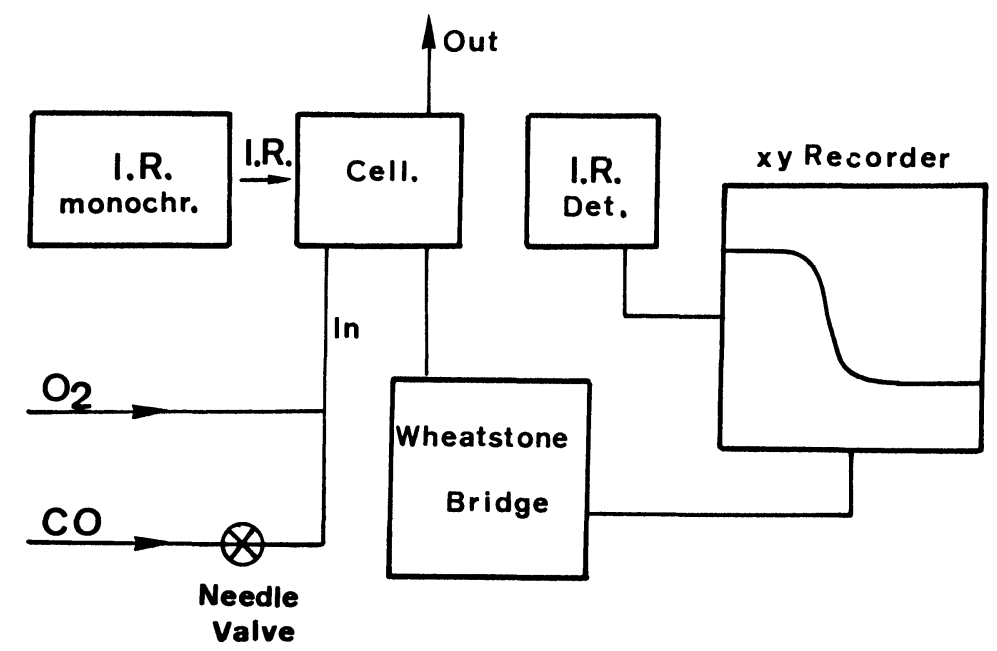

FIGURE 3 Experimental set-up for measurement of the inhibition point.

tion and diffusion unless very strong differences of these parameters exist between oxygen and carbon monoxide. That does not seem to be the case for PTFE.

In these conditions the rate of $\mathrm{CO}_{2}$ production by the surface unit of the catalyst for a membrane thickness $L$ is:

$\mathrm{J}_{\mathrm{CO}_{2}}^{\mathrm{L}}=\frac{\mathrm{D}_{\mathrm{CO}}}{\mathrm{L}}\left(\mathrm{S}_{\mathrm{CO}} \mathrm{C}_{\mathrm{CO}}^{\mathrm{g}}-\mathrm{C}_{\mathrm{CO}}^{1}\right)$

where $\mathrm{D}$ is the $\mathrm{CO}$ diffusion coefficient, $\mathrm{L}$ the membrane thickness, $\mathrm{c}^{\mathrm{C}} \mathrm{O}$ the $\mathrm{CO}$ concentration in gas phase, $\mathrm{C}_{\mathrm{CO}}^{1}$ the $\mathrm{CO}$ concentration at the interface 1 and $\mathrm{S}$ the $\mathrm{CO}$ solubility in PTFE.

The critical $\mathrm{CO}$ concentration $\left(\mathrm{C}_{\mathrm{CO}}^{1}\right)^{*}$ where the reaction inhibits and the corresponding value $\mathrm{J}_{\mathrm{CO}_{2}}^{*}$ are constants of the reaction and of the catalyst PTFE interface. They will be identical for any thickness $X$.

Then we can write:

$$
\left(\mathrm{J}_{\mathrm{CO}_{2}}^{\mathrm{X}}\right)^{*}=\frac{\mathrm{D}_{\mathrm{CO}}}{\mathrm{X}}\left(\mathrm{S}_{\mathrm{CO}}\left(\mathrm{C}_{\mathrm{CO}}^{\mathrm{g}}\right)_{\mathrm{x}}^{*}-\left(\mathrm{C}_{\mathrm{CO}}^{1}\right)^{*}\right)=\frac{\mathrm{D}_{\mathrm{CO}}}{\mathrm{L}}\left(\mathrm{S}_{\mathrm{CO}}\left(\mathrm{C}_{\mathrm{CO}}^{\mathrm{g}}\right)_{\mathrm{L}}^{*}-\left(\mathrm{C}_{\mathrm{CO}}^{1}\right)^{*}\right)
$$

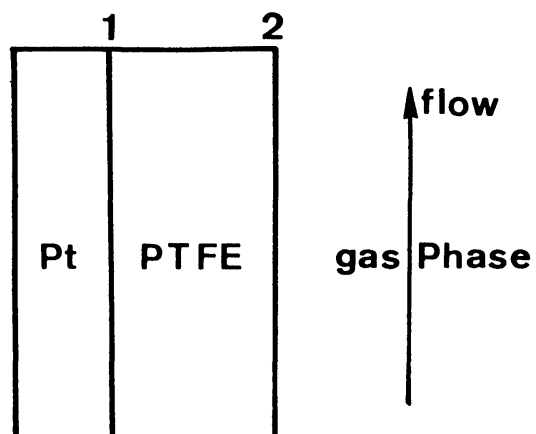

FIGURE 4 Scheme of the gas/PTFE/platinum-system. 
where the started values are taken at the inhibition point. So we obtain

$\left(\mathrm{C}_{\mathrm{CO}}^{\mathrm{g}}\right)_{\mathrm{x}}^{*}=\frac{\left(\mathrm{C}_{\mathrm{CO}}^{1}\right)^{*}}{\mathrm{~S}}+\left(\mathrm{C}_{\mathrm{CO}}^{\mathrm{g}}\right)_{\mathrm{L}}^{*}-\frac{\left(\mathrm{C}_{\mathrm{CO}}^{1}\right)^{*}}{\mathrm{~S}} \frac{\mathrm{x}}{\mathrm{L}}$

In Figure 5 we have plotted at $135 \mathrm{C}^{\circ},\left(\mathrm{C}_{\mathrm{CO}}^{\mathrm{g}}\right)^{*}$ determined by IR absorption for different membrane thicknesses as a function of the ratio $x / L, L$ being the thickness of reference. Examples of resistance variation are given in Figure 6. As was noted above the resistance ratio $\mathrm{R}_{\mathrm{O}_{2}} / \mathrm{R}_{\mathrm{CO}}$ is high for low $\mathrm{CO}$ concentrations and decreases rapidly when the percentage of $\mathrm{CO}$ to $\mathrm{O}_{2}$ is between 0.5 and 1.0. Above $1 \%$ the resistance ratio remains constant.

It is seen that a series of resistances covered with different thicknesses will be a series of switches which will be on or off depending on the $\mathrm{CO}$ concentration. They constitute a digital detector.

\section{DETERMINATION OF THE SOLUBILITY AND DIFFUSION COEFFICIENT OF CO IN PTFE}

In order to verify the correctness of our model we calculated from our measures the solubility and the diffusion coefficient of CO in PTFE.

The ordinate at $\mathrm{x} / \mathrm{L}=0$ gives us the ratio $\left(\mathrm{C}_{\mathrm{CO}}^{1}\right)^{*} / \mathrm{S}$ where $\left(\mathrm{C}_{\mathrm{CO}}^{1}\right)^{*}$ is the inhibition concentration without PTFE. Taking its value at $135 \mathrm{C}^{\circ}$ and putting it in the relation we have

$S=\frac{0.2110^{-7}}{1.6810^{-7}}=0.13$

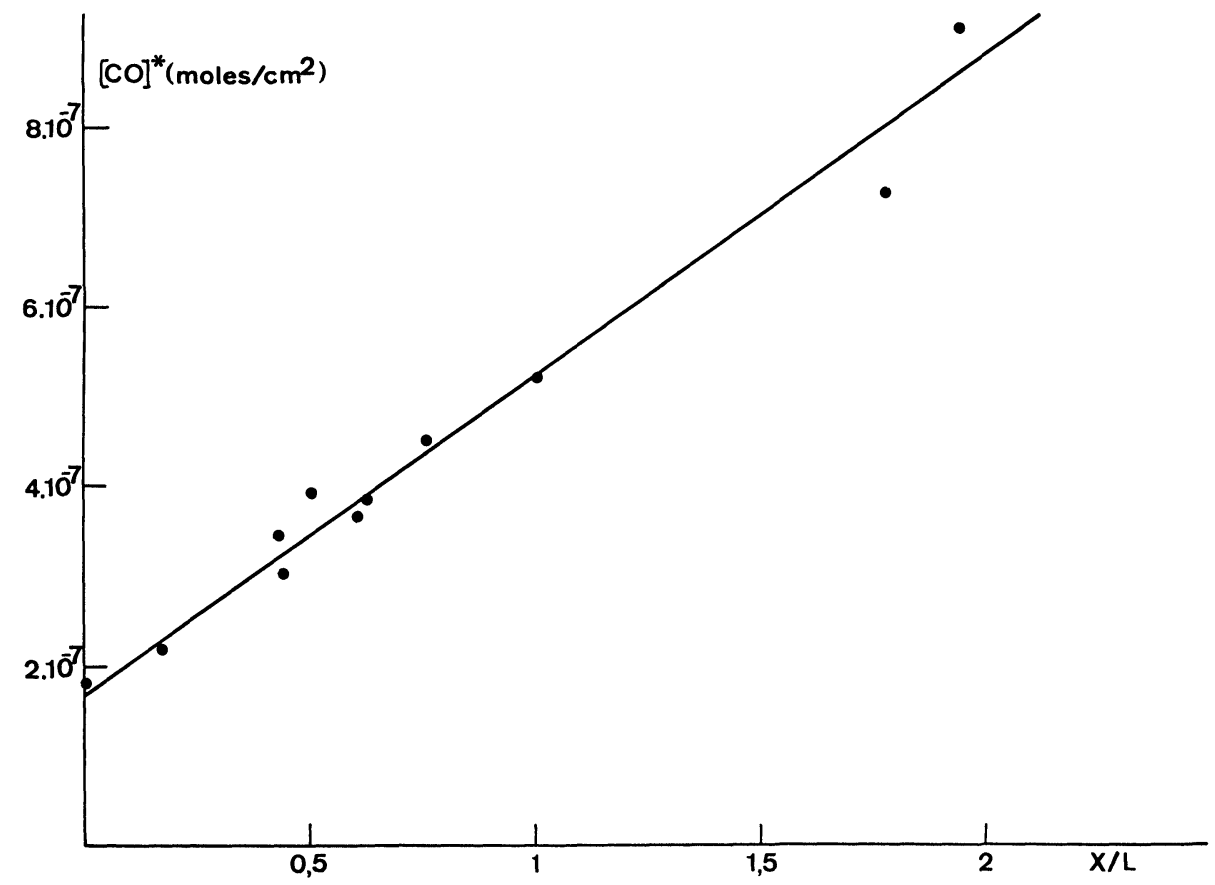

FIGURE 5 Plot of $\left(\mathrm{C}_{\mathrm{CO}}^{\mathrm{g}}\right) *$ as a function of membrane thickness $(\mathrm{L}=1800 \AA)$. 


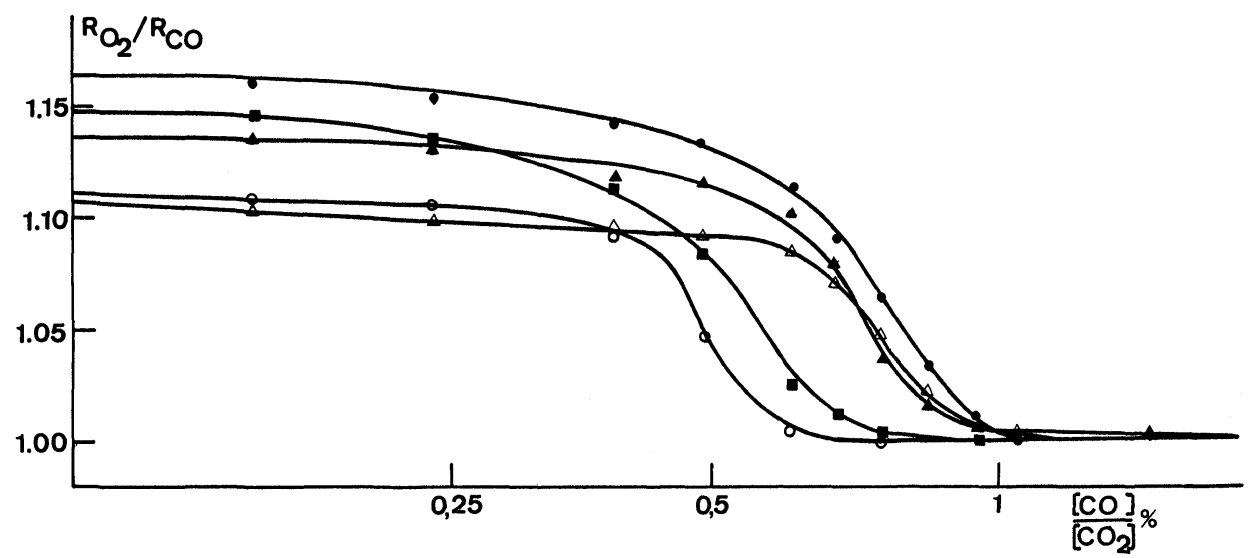

FIGURE 6 Relative resistance variation recorded versus the $[\mathrm{CO}] /\left[\mathrm{O}_{2}\right]$ ratio for different membrane thicknesses.

Knowing this value and the $\mathrm{CO}_{2}$ production at $\mathrm{C}_{\mathrm{CO}}{ }^{*}$ we have verified the expression to be correct with and without PTFE. One obtains the diffusion coefficient from the diffusion equation

$\mathrm{D}_{\mathrm{CO}}=\frac{\mathrm{J}_{\mathrm{CO}_{2}} \mathrm{~L}}{\left(\mathrm{~S}\left(\mathrm{C}_{\mathrm{CO}}^{\mathrm{g}}\right)_{\mathrm{L}}^{*}-\left(\mathrm{C}_{\mathrm{CO}}^{1}\right)^{*}\right)}=\frac{4.410^{-7} \times 180010^{-8}}{(0.13 \times 5.2-0.21) 10^{-7}}=1.710^{-4} \mathrm{~cm}^{2} / \mathrm{sec}$.

Taking as activation for diffusion 40 kjoules which is a mean value for gases in polymers 9 we obtain;

$\mathrm{D}_{\mathrm{CO}}^{25 \mathrm{C}^{\circ}}=2.2410^{-6} \mathrm{~cm}^{2} \mathrm{sec}^{-1}$

which is a good order of magnitude. ${ }^{9}$

\section{AGEING OF THE SAMPLES, PRECISION AND REPRODUCIBILITY}

Two samples were tested during a week at $135 \mathrm{C}^{\circ}$ the $\mathrm{C}^{*}$ o being measured twice a day. We observed an evolution to lower concentrations during the first 48 hours. After this period it stabilized at a value about $10 \%$ lower than at the beginning of the experiment. At this time the variation becomes lower than the sensitivity of the infrared detector $(<1 \%)$. The structure of the PTFE can influence the measure. An ESCA study of the PTFE films ${ }^{10}$ shows double bonds formation and cross linking but provided the discharge conditions of the sputtering are reproduced, the same type of PTFE is obtained.

The mean square deviation in our results is $7.1 \%$. It is obvious that if a standardisation of each element which will form the sensor is made, a precision at least ten times greater can be obtained (see the ageing test).

\section{REFERENCES}

1. J.P. Dauchot, J. Van Cakenberghe, Japan J. Appl. Phys. Suppl. 2, T 2, (1974).

2. J.P. Delrue, A. Hecq, M. Hecq, J.P. Dauchot, Proc. 7th Intern. Vac. Congr. and 3rd Intern. Conf. Solid Surfaces p. 2063 (Vienna 1977).

3. R. Dagonnier, M. Dumont, J. Nuyts, J. of Catalysis 66, 130-146 (1980).

4. J.P. Dauchot, ESSDERC 78, 3rd Symposium on solid state device technology (Montpellier, September 1978). 
5. D. Söderberg, I. Lundström, C. Swensson, Material Science and Engineering, 42 141-144 (1980).

6. M. Hecq, A. Hecq, J.P. Delrue, T. Robert, J. of Less-Common Metals, 6425 (1979).

7. H.W. Lehmann, K. Frick, R. Widmer, Thin Solid Films 52 No. 2231 (1978).

8. L.I. Maissel, R. Glang, Handbook of thin film technology, 11-8 McGraw Hill (1970).

9. J. Brandrup, E.H. Immergut, W. McDawell, Polymer Handbook 2nd Edition, J. Wiley \& Sons, Inc. (1975).

10. Laboratoire de Spectroscopie électronique, Facultés Notre-Dame de Namur B-5000 Belgique, Private communication.

11. Brevet Belge (1980) No 881.051. 

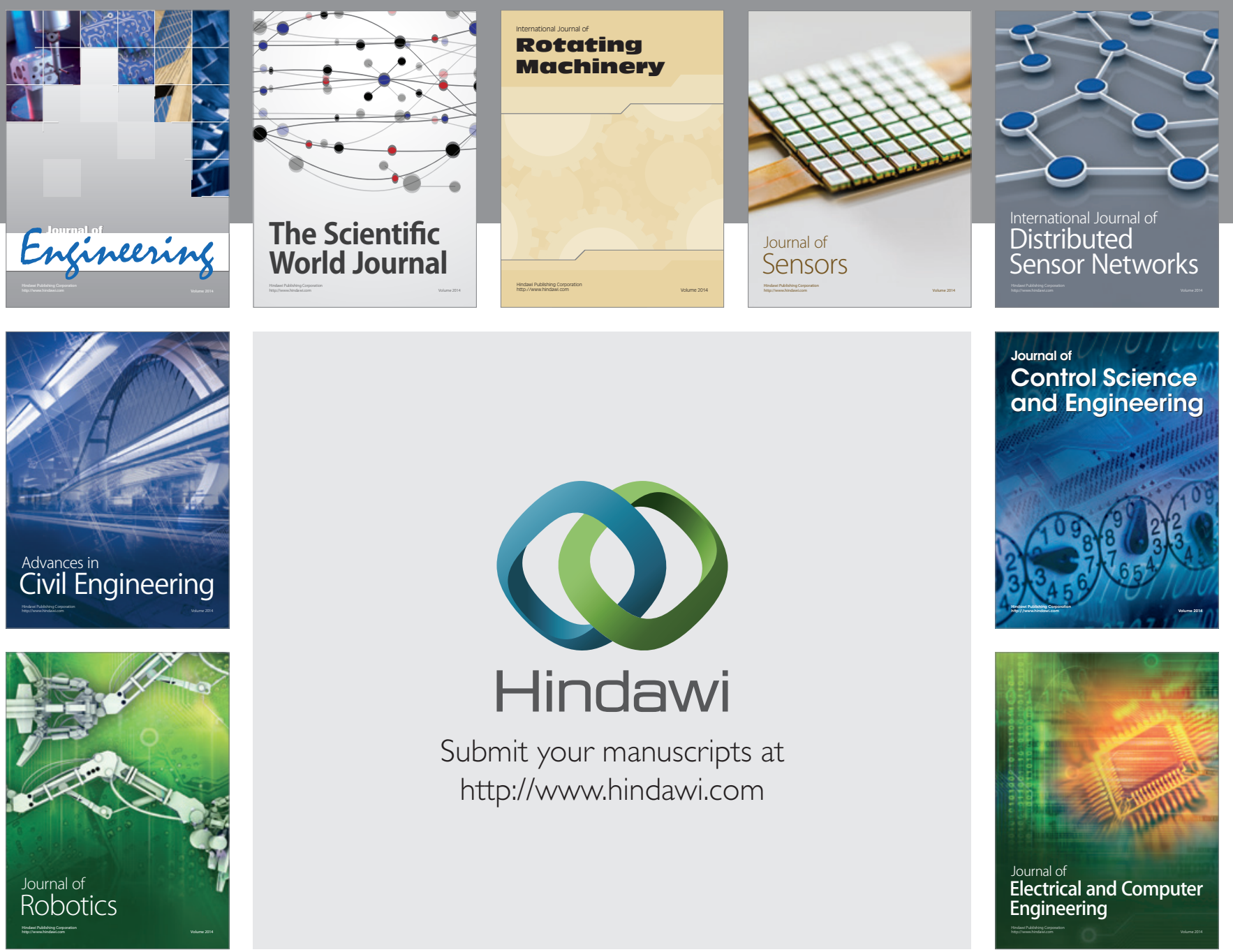

Submit your manuscripts at

http://www.hindawi.com
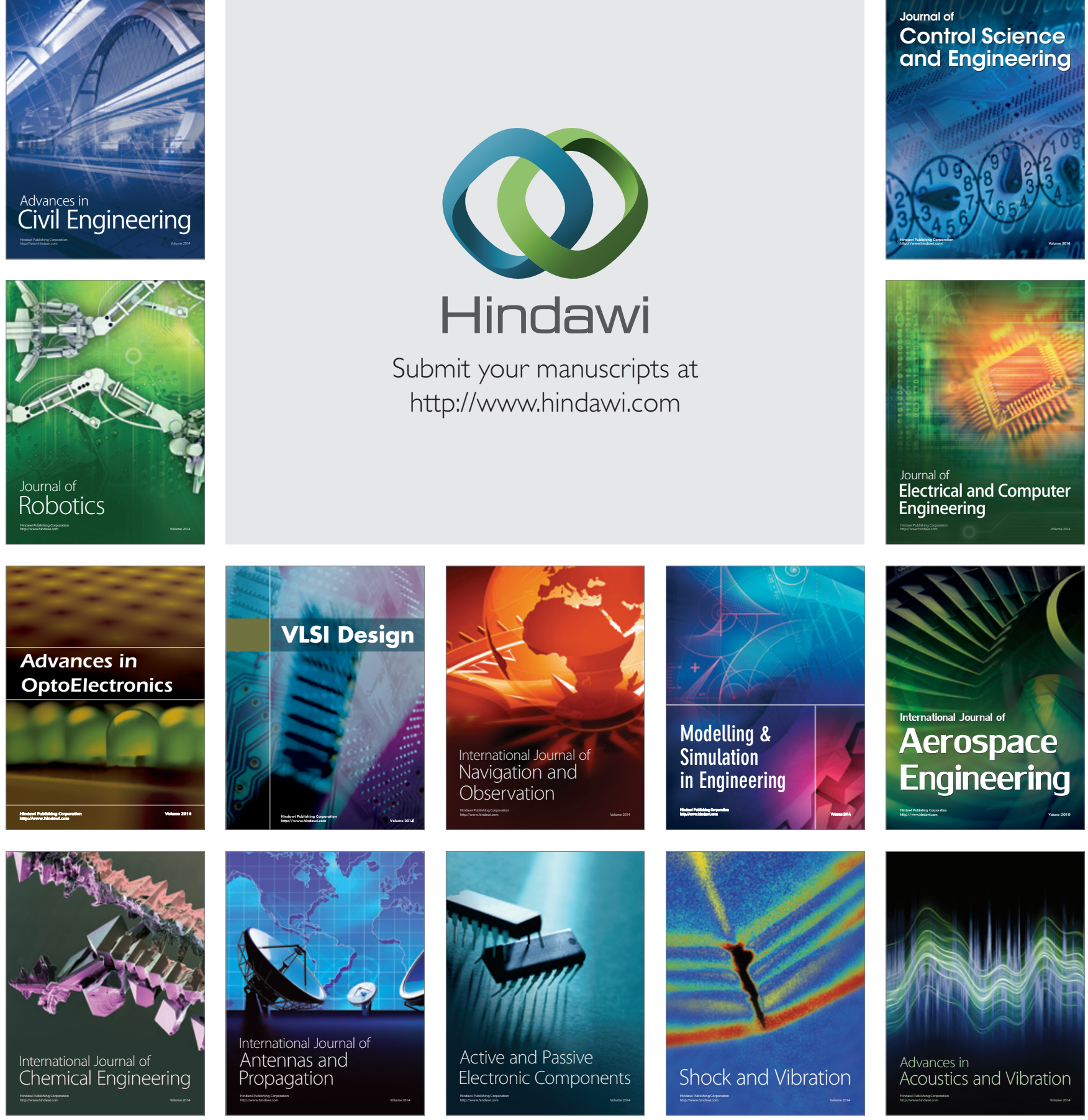